\title{
Ethos, símbolos e imaginário religioso de um grupo de praticantes de Jeet Kune Do
}

\author{
Matheus Oliva da Costa*
}

Resumo: Neste artigo realizamos um estudo de caso em um grupo de praticantes de Jeet Kune Do (JKD), arte marcial criada pelo ator e artista marcial Bruce Lee. Objetivam-se investigar o ethos e o imaginário dos praticantes de JKD na cidade de Montes Claros, localizada no sertão norte-mineiro, focalizando seus aspectos religiosos. Realizamos uma etnografia dos treinos no Instituto Erize de Artes Marciais, norteados pela antropologia de Clifford Geertz, e analisamos os símbolos iconográficos presentes no ambiente de treinamento, percebendo que os conceitos religiosos das tradições "orientais" representados nesses símbolos movimentam o imaginário religioso dos praticantes. São perceptíveis diferentes reações dos praticantes no contato com esses símbolos e conceitos de outras culturas, havendo vários tipos de hibridações culturais. Observamos que há um sentimento de pertencimento no grupo que favorece o surgimento de um ethos e uma visão de mundo próprias dos praticantes de JKD, onde a busca por eficácia e por uma autonomia criativa (fluir) são centrais.

Palavras-Chave: artes marciais, religiosidade, incorporação, imaginário, hibridação.

Observando treinos de diversos estilos de artes marciais de origem asiática, percebemos que existem elementos de corte religioso nessas práticas. Contudo, o tema ainda não recebeu a devida atenção pelos pesquisadores brasileiros. Baseando-se na necessidade de contribuir com essa demanda nas pesquisas em ciências humanas e sociais, no presente artigo, realizamos um estudo de caso em um grupo de praticantes de Jeet Kune Do (JKD), arte marcial criada em meados dos anos de 1960 e 1970 pelo ator e artista marcial Bruce Lee. Temos como objetivo investigar o ethos e o imaginário dos praticantes de JKD na cidade de Montes Claros, localizada no sertão norte-mineiro, focalizando seus aspectos religiosos.

Etnografamos os treinos e as atividades de JKD que ocorrem no Instituto Erize de Artes Marciais, fundamentados na antropologia de Clifford Geertz (1989 e 2009). Focalizamos nosso estudo nas reações originadas em praticantes de JKD pelo processo de encontro com elementos religiosos provenientes de outras culturas. Elementos esses que foram "importados" por essa arte marcial e por meios de comunicação. Buscamos compreender essas reações por meio da análise dos símbolos e da iconografia de corte religioso presentes no ambiente de treino dos pra-

\footnotetext{
* Graduando em Ciências da Religião - Unimontes. Bolsista do Programa de Educação Tutorial em Ciências da
} Religião pela CAPES, tendo como orientadora a prof ${ }^{\mathrm{a}}$ Cristina Borges. 
ticantes (DURAND, 2000 e 2002; APOLLONI, 2004), interpretando suas reações com a teoria do hibridismo cultural (BURKE, 2003; CANCLINI, 2006).

\section{O legado do Pequeno Dragão em Montes Claros/MG}

0 criador do Jeet Kune Do foi Bruce Lee, artista marcial nascido em 1940 na cidade de São Francisco (Estados Unidos), registrado como Lee Jun Fan. Mesmo tendo nascido nos Estados Unidos, era descendente de chineses e alemães. Seus pais levaram-no pouco após seu nascimento para Hong Kong, onde viveu até a juventude. Foi uma criança inquieta e encrenqueira, e isso acarretou desde apelidos - por exemplo, Siu Long (pequeno dragão) - a sérias consequências em sua vida. Ainda criança o Pequeno Dragão já participava de produções cinematográficas em Hong Kong (LOPES, 2006).

$\mathrm{Na}$ adolescência, suas "encrencas" foram motivo para o ingresso numa academia de artes marciais, onde foi aluno deYip Man, famoso mestre do estilo wing chun, arte marcial chinesa de "movimentos mais rápidos e econômicos, e ao mesmo tempo contundentes" (idem, p. 14). Segundo a obra biográfica Bruce Lee: definitivo de Marcio Lopes, Bruce "ficou fascinado com as aulas do mestre Yip, que envolviam também filosofia oriental, autocontrole emocional e metodologias de luta" (idem, ibidem), aspecto que o influenciou bastante. Em Hong Kong, Bruce treinava outros estilos de lutas com amigos, como o boxe inglês, chegando a ganhar campeonatos estudantis.

Jovem, retornou à sua cidade natal para viver sozinho, seguindo viagem em 1959. Aos 21 anos, após ter se mudado para Seattle, entrou para a Universidade de Washington, onde cursou filosofia: "como gostava de ler, a faculdade poderia aprimorar sua bagagem de professor de kung fu" (idem, p. 22). Nesse período, começou a ensinar artes marciais a estudantes da universidade, e, mais tarde, com o sucesso das aulas, abriria o Instituto Lee Jun Fan Gong Fu, onde conheceu a sua esposa Linda Lee. Após casar-se com ela, em 1964, mudou-se para Oakland (Estados Unidos). Bruce estava inserido em uma sociedade híbrida. Devemos lembrar que no período pós-guerra (Segunda Guerra Mundial) bem como durante a Guerra do Vietnã os Estados Unidos receberam imigrantes de diversas regiões do mundo, e 
essa hibridez se refletia nos alunos do seu instituto, como também nos estilos que treinava. Dois pontos centrais na sua arte marcial eram a eficiência das técnicas e a adaptação da técnica ao artista marcial, o que era possível somente experimentando várias técnicas. Isso certamente resultava em uma hibridação das técnicas marciais.

Bruce também dizia que nem ensinava mais o kung fu tradicional, modalidade que ele passara a considerar como limitada. [...] 0 que ele lecionava na academia em Oakland era uma mistura das técnicas que aprendera no wing chun, como boxe, jiu jitsu, boxe tailandês e karatê (idem, p. 24).

Como resultado de treinamentos intensificados, chegou a ser hospitalizado por uma séria lesão. No entanto, usou seu tempo para reflexão: "aproveitou para tentar colocar no papel algo que vinha elaborando nos últimos anos - as bases de um novo estilo de luta oriental" (idem, p. 32). Assim nascia o Jeet Kune Do (JKD).

A leitura de obras de outros artistas marciais (Edwin L. Haislet, boxeador, e Julio Martinez Castello, mestre de esgrima ocidental), obras de religiões como o taoísmo e o zen budismo, bem como as ideias do pensador indiano Jiddu Krishnamurti, serviram como fundamentação teórica ao JKD. Bruce Lee tentou realizar uma obra que mostrasse como ele enxergava as artes marciais e ao mesmo tempo apresentasse a base teórica do seu próprio sistema: "No livro, chamado Tao of Jeet Kune Do (O Tao do Jeet Kune Do), teorizou os fundamentos e a filosofia do estilo" (idem, p. 36). Percebemos nesse livro e em outros escritos de Bruce Lee uma forte influência das religiões citadas acima: o taoísmo e o budismo (em especial a escola zen).

A presença dessas religiões se dá de duas formas, uma é explicita no livro, outra pode ser vista somente nas entrelinhas. Exemplos mais explícitos são: o subcapítulo denominado "Zen", que inclui um trecho com "os oito mandamentos do budismo" - outro nome dado ao caminho óctuplo budista - e o capítulo "Circulo sem circunferência", em que cita vários termos próprios do budismo (nirvana, paj$n a$ ) e do taoísmo (vazio, fluidez, yin/yang). Também pode ser vista uma influência mais sutil: Bruce afirma em $O$ Tao do Jeet Kune Do que é necessário deixar a mente em estado de vazio e fluidez, já que dessa forma poderia "mover-se com totalidade", pois "não ter técnica, é ter todas as técnicas" (LEE, 2003, p. 227). Esse estado 
de fluidez ou vazio, para o taoísmo, significa a supressão do ego, possibilitando que o Tao atue no ser humano, um estado natural. Assim como nos textos taoístas, nos escritos de Bruce, estar no estado mental do vazio seria agir naturalmente, e, por isso, toda e qualquer técnica flui espontaneamente para o artista marcial. Veremos que a noção de fluir é constitutivo do ethos dos praticantes de JKD em Montes Claros.

Ainda nesse mesmo livro, Bruce sugere a leitura de Krishnamurti, do zen e do taoísmo para o desenvolvimento mental. Jiddu Krishnamurti foi um pensador indiano conhecido na Europa e nos Estados Unidos em meados do século XX. Esse pensador influenciou Bruce principalmente no aspecto crítico de ver o mundo. Com todas essas influências, e com a hibridação delas, é concebido o Jeet Kune Do (JKD), que pode ser traduzido como Caminho (Do) do Punho (Kune) Interceptador (Jeet).

Sobre o emprego do termo Do, este é um termo em japonês, estando os demais em mandarim, apontando para a influência do zen budismo em sua versão nipônica. Isso confirma a tese de Apolloni (2004) quanto a um "olhar nipônico" das artes marciais pelos praticantes europeus e americanos, referindo-se ao entendimento de que as artes marciais têm finalidades espirituais, entendimento próximo da forma japonesa de ver a marcialidade. Para Apolloni, as artes marciais chinesas não têm corte religioso. Concordamos com esse autor, uma vez que percebemos isso entre os praticantes de JKD em Montes Claros, contudo, isso não significa que não existem elementos de natureza religiosa nas artes marciais chinesas, pois Apolloni também mostra como a marcialidade chinesa está envolta em conteúdos culturais que incluem mitos marciais, divindades protetoras dos estilos, gestos e saudações vindas do budismo e símbolos de origem religiosa.

Portanto, sendo o JKD uma arte marcial chinesa - lembrando também das suas outras fontes (Krishnamurti, zen japonês, outras artes marciais) - entendemos que ela não tem corte religioso, muito menos seria uma religião. Por outro lado, apresenta um conteúdo cultural proveniente da China e do Japão, recheados de símbolos, mitos, saudações, gestos e ensinamentos provenientes de fontes religiosas, mais exatamente do taoísmo e do zen budismo. Destarte, seus praticantes entram em contato não somente com técnicas corporais de autodefesa, mas com 
toda uma gama de elementos "filosóficos", terapêuticos, marciais e também religiosos.

Essa arte marcial - e o seu conteúdo - foi transmigrada para outras regiões do mundo, uma vez que Bruce Lee teve centenas de alunos. No entanto, somente alguns deles tiveram destaque reconhecido. Segundo a apostila escrita, editada e distribuída no Instituto Erize de Artes Marciais pelo coordenador dessa instituição e professor de JKD Ruysdael Crise Pereira Soares, seriam três discípulos formados por Bruce: Daniel (Dan) Inosanto, Taki Kimura e James Lee.

Em entrevista realizada no dia 4 de janeiro de 2011, esse mestre de JKD de Montes Claros nos relatou que Dan Inosanto foi o mestre de Paul Vunak, que por sua vez ensinou ao brasileiro Roberto Pereira, que entre os anos de 1970 e 1980 estaria vivendo nos Estados Unidos. Segundo Ruysdael, o mestre Roberto Pereira teria treinado também com Robert (Bobby) Giordano, artista marcial nos Estados Unidos. Mais tarde, já como professor de JKD, retornou à sua cidade natal no Brasil, Governador Valadares (MG), sendo então o responsável pela transmigração do JKD ao estado de Minas Gerais. Importante esclarecer que nos referimos aqui estritamente à trajetória do JKD que chegou a cidade de Montes Claros.

Em visita a cidade de Governador Valadares, Ruysdael conheceu a academia do mestre Roberto. Ao aprovar o sistema de treinamento começou a treinar JKD. Quando já formado num nível em que é permitido ministrar aulas, retornou a Montes Claros, onde em pouco tempo abriu sua própria academia (Instituto Erize) no ano de 1993. Nas entrevistas e conversas informais, praticantes antigos e o próprio Ruysdael relataram que o mestre Roberto teria vindo várias vezes a Montes Claros para ministrar treinos e graduar alguns alunos, confirmando a genealogia do JKD do Mestre Ruysdael.

É interessante, nesse momento, descrevermos o contexto cultural onde estudamos os praticantes de JKD. Montes Claros localiza-se no sertão norte-mineiro, e por sertão norte-mineiro nos referimos à toda região norte do estado de Minas Gerais. A cientista da religião Cristina Borges (2011, p. 26) afirma que essa terra "pertence à região Sudeste, mas possui características semelhantes ao nordeste brasileiro", no aspecto geográfico, sociocultural e econômico, "sendo, portanto, 
uma área de transição" entre o sul do estado da Bahia e o centro do estado de Minas Gerais.

Inicialmente, a região ficou longe do poder colonizador dos portugueses, fazendo com que sua população forjasse uma cultura à parte da que estava sendo moldada em outros locais no Brasil, e mesmo de outras regiões do estado de Minas Gerais, já que seu processo histórico de povoamento se distingue da região mineradora. 0 norte desse estado possuía uma economia predominantemente agropecuária e pastoril, levando a ser conhecido por Currais da Bahia. Outra característica dessa região é a existência, em sua história, de vários povos que dividiam o espaço, como os Tapuia, os Xacriabá, os negros quilombolas e os portugueses.

Muitos desses povos fugiam das "rédeas" da coroa portuguesa, numa atitude de resistência, como alguns indígenas e quilombolas, ou por motivos criminais, caso dos bandidos e fugitivos que buscavam se esconder nas profundezas do sertão. Os dois exemplos foram elementos que alavancaram um clima de instabilidade na região, que com o passar do tempo contribuiu para o caráter violento da região. Tal contexto alia-se ao processo de legitimação do poder independente da máquina estatal por grandes latifundiários, que por estarem longe dos olhos de Portugal não pagavam os tributos e impostos, gerando assim grandes lucros para si. Ao longo dos séculos, os donos de terra tornaram-se poderosos, criando, com liberdade, suas próprias leis. Isso sugere o surgimento de uma cultura marcada pela liberdade, por uma moral própria e pela violência, características necessárias para viver em um mundo regido pela instabilidade.

O sertão norte-mineiro formou-se num território de fronteira entre povos distintos, propiciando uma especificidade regional: a criação de uma sociedade de fronteira (BoRGES, 2011). Na mesma linha de entendimento, o antropólogo João Batista Costa (2003, p. 310) explica, baseado em Homi Bhabha, que essa terra se encontra em um entre-lugar, ou seja, um "espaço intersticial entre duas partes vinculadas solidariamente entre si”. Essa situação ajudou a construir um sistema simbólico aberto e híbrido nos povos norte-mineiros, aberto pela necessidade de adequação e sobrevivência, híbrido, justamente, por haver uma constante negociação cultural dos povos que se encontram nesses entre-lugares. As trocas culturais com 
o sul da Bahia e a região mineradora, bem como a diversidade no interior do norte de Minas Gerais, geram uma identidade regional baianera.

No aspecto religioso do norte de minas, Costa defende que há uma "hibridação de elementos do cristianismo, com elementos da vida religiosa africana" (2003, p. 186; grifo do autor), além de haver mistura com elementos indígenas da tradição Xacriabá, miscelânea já sugerida pelo ethos dos povos dessa região. Atualmente, no norte de Minas há uma forte tradição do cristianismo católico, sendo encontrado também o protestantismo histórico, denominações cristãs pentecostais e neopentecostais, religiões de matriz afro como o candomblé, a umbanda e a quimbanda, religiões de matriz asiática (budismo, novas religiões japonesas), esoterismos, movimento Nova Era e todo tipo de religiosidade popular sertaneja.

\section{Hibridismo cultural, norte-mineiros e Jeet Kune Do}

0 Jeet Kune Do se formou tendo como referência diversas fontes e influências, tanto teóricas - taoísmo, zen budismo, Krishnamurti - quanto práticas - diversos estilos de artes marciais, principalmente wing tsun e boxe. Dessa forma, é uma prática híbrida. Essa arte marcial foi transmigrada ao sertão norte-mineiro, que, como vimos, é um entre-lugar geográfico e cultural, que como tal possui identidade própria. Elegemos, pois, a perspectiva do hibridismo cultural como lente teórica para o nosso estudo.

O antropólogo Néstor Garcia Canclini (2006, p. XIX) entende por hibridação "processos socioculturais nos quais estruturas ou práticas discretas, que existiam de forma separada, se combinam para gerar novas estruturas, objetos e práticas”. No caso da região norte-mineira, é perceptível como diferentes estruturas culturais coexistem no mesmo espaço: povos nativos, quilombolas, poder estatal, fazendeiros, (descendentes de) portugueses, economia agropastoril e mineradora (enquanto exceção). Apesar de os muitos povos existentes não se terem reunido em uma mesma sociedade, mas ao contrário, viverem separados, podemos afirmar a existência de trocas culturais entre eles, aludindo assim a processos de hibridismo cultural que reflete a situação geográfica de entre-lugares. 
Ora, como afirma Peter Burke (2003, p. 31), “devemos ver as formas híbridas como o resultado de encontros múltiplos e não como o resultado de um único encontro". É o que ocorre no sertão norte-mineiro e com o JKD. Sobre esses processos de encontro, Canclini (2006, p. XXII) afirma que "às vezes, isso ocorre de modo não planejado ou é resultado imprevisto de processos migratórios [...]. Mas frequentemente a hibridação surge da criatividade individual e coletiva". Enquanto a cultura norte-mineira seria um caso de uma criatividade coletiva, o JKD apresenta-se como uma hibridação nascida - inicialmente - da criatividade de Bruce Lee. No entanto, ambos os casos de hibridação demonstram que esse processo favorece a criação de novos valores, também implicando constantes adaptações.

Quando afirmamos o caráter híbrido dessa arte marcial e dessa região, não estamos apresentando um diferencial destes, mas uma especificidade. Pensando pela perspectiva de Canclini (2006), compreendemos que, na contemporaneidade, há em todas as culturas alguma hibridação, estando esses processos em diversos níveis. $\mathrm{O}$ autor comenta que os encontros culturais na contemporaneidade acontecem muito mais por meios de comunicação como a internet, livros ou produções culturais, do que de forma direta. A atual rapidez com que nos defrontamos com as informações, mundialmente, favorece as trocas culturais e até as incentiva. Contudo, Burke (2003) mostra que o fenômeno das trocas culturais está envolto em uma enorme complexidade, existindo variedades de objetos, termos, situações, reações e até de resultados em relação aos encontros culturais.

Aplicando alguns dos seus conceitos ao nosso assunto, podemos dizer que o JKD é uma prática híbrida em sua origem e em seu desenvolvimento. Em termos marciais, houve uma apropriação de diversos estilos de artes, numa seletiva das técnicas que julgou como mais eficientes e diretas, sem, contudo, alterar sua teoria sobre as artes marciais, o que também pode ser chamado de empréstimo (cultural). A criação do JKD se deu num contexto de "dupla nacionalidade" de Bruce Lee, já que passou parte da vida nos Estados Unidos e parte em Hong Kong, propiciando traduções culturais de mão dupla. Para interpretar esse último tipo de reação, evocamos o conceito de circularidade cultural, em que há readaptações cíclicas: Bruce Lee, tendo começado a participar de filmagens desde criança em Hong Kong, consegue entrar na indústria de filmes americana, onde introduz coreografias de lutas 
com características mais chinesas na produção hollywoodiana, que, por sua vez, influenciou posteriormente os filmes de luta chineses ${ }^{1}$.

Esses exemplos ilustram algumas das múltiplas possibilidades das trocas culturais. Com eles, queremos mostrar que existe mais do que uma simples troca cultural, havendo uma complexidade nos fenômenos estudados no presente trabalho. Por hora, realizamos um recorte, focalizado nos elementos religiosos presentes no JKD e nas reações dos praticantes a esses elementos.

Nesse sentido, dois pontos devem ser trazidos à tona. Primeiramente, o $e$ thos do povo norte-mineiro remete à violência presente em sua formação histórica: tal contexto de violência talvez explique a procura por artes marciais, já que também são formas de autodefesa. Importante lembrar que a violência social na região do mosteiro de Shaolin na China seria uma das causas atribuídas para o nascimento e desenvolvimento das artes marciais chinesas, como mostra as obras de Apolloni (2004) e Shahar (2003). Em segundo lugar, a cosmologia do sertão nortemineiro e do JKD apresenta uma semelhança: a busca por liberdade. 0 povo nortemineiro desenvolveu-se em ambiente de liberdade, longe dos domínios do poder colonial. Por sua vez, Bruce Lee, que apesar de ter vivido em outro contexto e em outra cultura, também tinha forte apreço pela liberdade: "a expressão deve ser livre. Essa verdade libertadora torna-se realidade apenas na proporção em que é experienciada e vivida como tal pelo próprio indivíduo" (LEE, 2007, p. 135). Possivelmente, essa característica chama a atenção dos praticantes norte-mineiros de JKD.

Se por um lado o JKD e a cultura sertaneja apresentam convergências e aproximações, por outro, pode ser conjecturado um possível impasse: a religiosidade presente no norte de Minas transparece ser distante das influências dessa prática. Como, então, o JKD teria espaço na sociedade sertaneja, uma vez que carrega em si elementos religiosos aparentemente tão distantes dessa realidade? Buscamos responder essa questão com os próprios praticantes de JKD por meio da pesquisa empírica.

\footnotetext{
1 Ver o documentário presente nos extras do filme Operação Dragão.
} 
Realizamos uma etnografia dos treinos de JKD (participamos dos treinos em diversos horários), aplicamos questionários e entrevistas. Na etnografia, tivemos como referência Clifford Geertz, cuja obra $A$ interpretação das culturas (1989)salienta que o pesquisador deve realizar uma descrição densa da cultura, ser capaz de interpretar o significado das ações, das pessoas, dos objetos, dos espaços culturais por vezes constituídos de uma estrutura complexa, irregular e não explícita, enfim, interpretar as evidências simbólicas.

Os questionários foram aplicados entre 15 e 18 de setembro de 2010, com 13 praticantes de 16 a 37 anos, sendo 12 homens e uma mulher. Com os questionários observamos que o tempo de treinamento era condição necessária para um maior envolvimento com o conteúdo teórico dessa arte marcial. Percebemos também na maioria deles um envolvimento com a religiosidade presente nessa prática. Dessa forma, usamos como critério o mínimo de seis meses de treinamento para as entrevistas.

Aplicamos entrevistas semiestruturadas entre os dias 17 e 29 de dezembro de 2010 com 11 praticantes, sendo dez homens e uma mulher entre 16 e 34 anos de idade, gravada em áudio. Segundo Ruysdael, o Instituto Erize consta com cerca de 50 a 60 matriculados, 11 entrevistados são, dessa forma, um número considerável, e por isso representam o universo dos praticantes de JKD, já que são mais de $20 \%$ do total. A entrevista com o mestre Ruysdael ocorreu separadamente, no dia 4 de janeiro de 2011. Em sua aplicação buscamos entender 1) o motivo que levou a treinar, 2) o nível de envolvimento e identificação com a prática, 3) o imaginário acerca de Bruce Lee, 4) tensão ou não com sua própria religiosidade, e 5) o nível de aproximação com culturas e religiosidades de tradição asiática.

\section{Teoria do imaginário e os símbolos do Jeet Kune Do}

Uma vez que procuramos entender as reações dos praticantes de JKD no que se refere ao encontro com a religiosidade presente nessa arte marcial, a teoria do imaginário é uma interessante ferramenta de análise da sua iconografia, bem como instrumento interpretativo do imaginário religioso desses praticantes, mediante o processo de encontro cultural. Em As estruturas antropológicas do imaginá- 
rio (2002), Gilbert Durand conceitua o imaginário da seguinte maneira: "Imaginário - ou seja, conjunto de imagens e relações de imagens que constitui o capital pensado do homo sapiens - aparece-nos como uma grande denominador fundamental onde se vêm encontrar todas as criações do pensamento humano" (p. 18).

Para esse autor, os símbolos devem ser explicados pelos símbolos - ideia inspirada no "frutuoso mandamento de Bachelard: 'A imagem só pode ser estudada pela imagem'” (idem, p. 19). Essa constatação fundamenta-se na compreensão de que os símbolos encontram-se em redes, ou melhor, em constelações isomorfas onde há uma convergência dos sentidos. Podemos resumir da seguinte maneira a organização dessas constelações simbólicas: existem os "simples símbolos", arquétipos, esquemas simbólicos, estruturas, e finalmente, os regimes do imaginário. Para o presente estudo, fazemos das noções de símbolo e arquétipo base para as nossas interpretações e análises.

Em Durand (2002), os símbolos são ambivalentes e/ou polivalentes, ou seja, comportam e originam diversos significados, assim, cada símbolo tem uma significância em cada grupo ou cultura, podendo expressar diversos significados mesmo no nível local. Tal noção mostra-se adequada para compreender o simbolismo presente no JKD, já que os símbolos dessa arte marcial são próprios das culturas e religiões asiáticas, que não são "nativas" da cultura norte-mineira. Portanto, cada praticante pode ter (re)significado o conteúdo dessa prática de diferentes formas, inclusive no que se refere ao seu conteúdo religioso. Os arquétipos, por sua vez, são desprovidos de tal ambivalência, tendo um caráter mais geral e universal. Para exemplificar, o gesto corporal de uma mão fechada seria um arquétipo do combate, da luta: basta fechar fortemente a mão diante de uma pessoa e observar sua reação para perceber que se trata de um arquétipo do enfrentamento. 0 arquétipo seria então um símbolo que sintetiza significados de uma rede de símbolos convergentes e isomórficos.

Sendo que encontramos símbolos e arquétipos em todas as sociedades, podemos afirmar que o imaginário existe em cada ser humano, e manifesta-se de diversas formas em culturas e grupos sociais diferentes. Em cada cultura, em cada sociedade existe um conjunto de valores e significados que se constituem como sentidos da existência: nas palavras de Durand (2000), homos animal symbolicum. 
Acreditamos que isso também se dá em pequenos grupos, por exemplo, praticantes de artes marciais.

Outra perspectiva de entendimento dos significados culturais é a de Clifford Geertz (1989). Para o autor, símbolos podem ser descritos "como qualquer objeto, ato, acontecimento, qualidade ou relação que serve como vínculo a uma concepção - a concepção é o 'significado' do símbolo" (p. 105). Notamos que a noção de símbolo de Durand (2000 e 2002) não só é compatível com a de Geertz (1989) como a complementa, já que para este os símbolos não só têm um significado como também são o próprio significado. Adotando a perspectiva de Geertz (1989) e ao mesmo tempo de Durand (2000), analisaremos alguns símbolos iconográficos presentes no ambiente de treino do JKD em Montes Claros (Instituto Erize), entendendo que neles são mais bem expressos o conteúdo implícito, o significante e o significado, presentes na visão de mundo dos praticantes dessa arte marcial. Apesar de existirem muitos símbolos iconográficos nessa academia de artes marciais, restringir-nos-emos a interpretar três.

Começamos com o símbolo criado pelo próprio Bruce Lee para o JKD (figura 1). No Dicionário dos símbolos (2008), Chevalier e Gheerbrant explicam a imagem do tai chi (no centro): "0 simbolismo do yin-yang exprime-se através [sic] de um círculo dividido em duas metades iguais por uma linha sinuosa, uma parte preta (yin) a outra branca (yang)" e lembram que "ainda é preciso observar que a metade yin contém um ponto yang e a metade yang um ponto yin, sinal da interdependência" (p. 968). Sobre o símbolo do tai chiApolloni (2004, p. 134) afirma:

\footnotetext{
O termo Tai-Chi pode ser traduzido do chinês, por aproximação, como "o mais alto", "o maior", "o grau supremo" ou "aquele que, por sua grandeza, não é mensurável". Seu conceito nasceu provavelmente dentro do Taoísmo, filosofia/religião chinesa por excelência, [...] a representação do Tai-Chi mostra as duas polaridades universais, Yin e Yang, interagindo dinamicamente.
} 


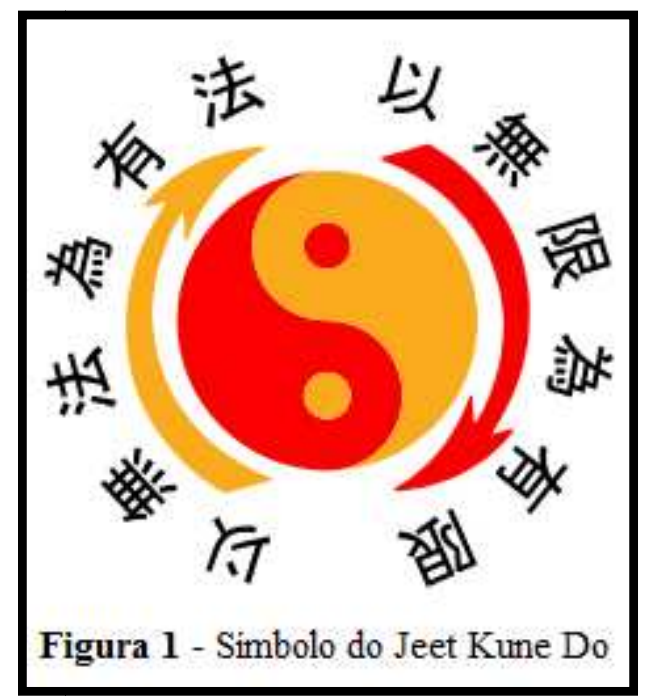

As setas ao redor do tai chi são elementos criados por Bruce Lee, e não encontramos nenhuma referência mitológica ou religiosa anterior. Na entrevista, o mestre Ruysdael disse-nos que as setas estão em sentido oposto ao sentido de rotação do tai chi - enquanto o tai chi estaria girando para a esquerda, as setas giram para a direita. De acordo com ele,

Tai chi significa o caminho normal do universo. Padrão, padronizado. E que as duas setas ao contrário [indicam que] você pode quebrar essa harmonia. [...] 0 caminho do universo você pode mudar, você pode redirecionar, do ponto de vista técnico (entrevista concedida em janeiro de 2011).

Ou seja, as setas simbolizam justamente o jeet (o interceptar) do Jeet Kune Do. Esse é um primeiro exemplo de como Bruce Lee usava de símbolos para expressar o conteúdo teórico da sua arte marcial. Ruysdael afirmou que é "do ponto de vista técnico", contudo, esse ponto de vista aparece em um símbolo, símbolo este que revela uma cosmovisão, a de que podemos, se necessário, romper com o "modelo" ou "padrão", para o desenvolvimento (pessoal ou coletivo). Para dizer em linguagem comum dos praticantes, de "evolução". Essa cosmovisão sempre está associada ao sentido prático ou marcial do JKD.

Em volta do tai chi e das setas existem alguns ideogramas chineses, eles significam: (à esquerda) "tendo nenhum caminho como caminho" - aqui Bruce Lee realizou uma ressignificação do caminho $(d o)$ zen budista, ou mais exatamente da teoria da não mente (mushin), e, ao mesmo tempo, uma hibridação com a lógica 
taoísta de que "uma via que pode ser traçada não é a Via eterna, o Tao", presente no primeiro verso do Tao Te Ching (LAOTsÉ, 1988); e (à direita) "tendo nenhuma limitação como limitação", referindo-se à experiência individual que não se deve limitar a modelos pré-estabelecidos, sendo uma influência de Krishnamurti. 0 pensador indiano valorizava a investigação interna e autônoma, livre de "autoridades externas", segundo Carneiro (2009, p. 21).

As cores amarelo e vermelho, presentes no símbolo do JKD, repetem-se no simbolismo do Instituto Erize. Para Chevalier e Gheerbrant (2008, p. 40), o amarelo simboliza o "intenso, violento, agudo até a estridência, ou amplo e cegante como um fluxo de metal em fusão, o amarelo é a mais quente, a mais ardente das cores", sendo também a cor que representa a "completa harmonia do yin e o yang." (idem, p. 41). Em culturas do extremo oriente o vermelho "evoca de uma maneira geral o calor, a intensidade, a ação" (idem, p. 946). Sendo o símbolo uma epifania de um mistério (DURAND, 2000), essas cores fazem aparecer concepções centrais da cosmologia do JKD, a complementaridade das polaridades e a movimentação constante, tanto do universo como do lutador.

Quando o mestre Roberto Pereira trouxe o JKD para a cidade de Governador Valadares, em Minas Gerais, ele levou não só um conjunto de técnicas corporais criadas e reformuladas por Bruce Lee mas também carregou consigo os símbolos, os gestos, as histórias, o imaginário, o ethos e a visão de mundo próprias dessa arte marcial e do grupo que a praticava. Esses elementos chegaram, entretanto, em uma sociedade que os tinha como estranhos: dos anos de 1970 até a década de 1990, a chamada Nova Era motivava temor e aversão religiosa por parte de alguns setores do cristianismo, religião da grande maioria dos brasileiros. E o mestre Roberto está incluso nessa maioria, pois, ele seria cristão protestante. Acreditamos, pois, que sua opção religiosa o motivou retirar o tai chi no centro do símbolo do JKD, como pode ser visto na figura2, seja por preferência pessoal, seja para evitar possíveis confusões entre o conteúdo da prática e a sociedade, já que naquele momento as pessoas poderiam ligar o JKD com a Nova Era. No lugar do tai chi, colocou-se a imagem de uma mão fechada verticalmente ("cerrada"), que, segundo Ruysdael, simboliza "força, estabilidade" e também "soco do sol, que é mais utilizado no wing tsun" (entrevista concedida em janeiro de 2011). 
Ruysdael disse-nos que por existir muitas academias (de artes marciais) no Brasil, a imagem do "soco do sol" é um diferencial e identifica a linhagem do mestre Roberto. Acrescido ao símbolo há apenas as palavras em inglês "street fighting" (ver figura 2), o que indica que o JKD seria uma luta para se defender dos perigos da rua, que é para ser usado em situações de perigo e não em campeonatos ou competições. As cores apenas mudaram de lugar - a circunferência está toda vermelha e as duas setas amarelas.

Também foi criado o símbolo da linhagem própria do mestre Ruysdael, com a ajuda do seu primeiro aluno (figura 3): o ideograma chinês no centro significa interceptar (jeet), enfocando essa característica do JKD. As setas indicam o movimento constante do universo, suprindo assim parte da simbologia do tai chi. A faca e os bambus aludem ao uso de armas nessa arte marcial, armas também utilizadas nas artes marciais filipinas. Nesse sentido, a faca e os bambus - ou bastões - têm a função de identificação com a linhagem iniciada por Dan Inosanto, mestre que está na origem da tradição que chegou a Montes Claros, sendo também a maior autoridade atual do JKD no mundo. 0 formato triangular é uma homenagem ao estado de Minas Gerais, sendo, assim, um símbolo de identificação com a região de origem.

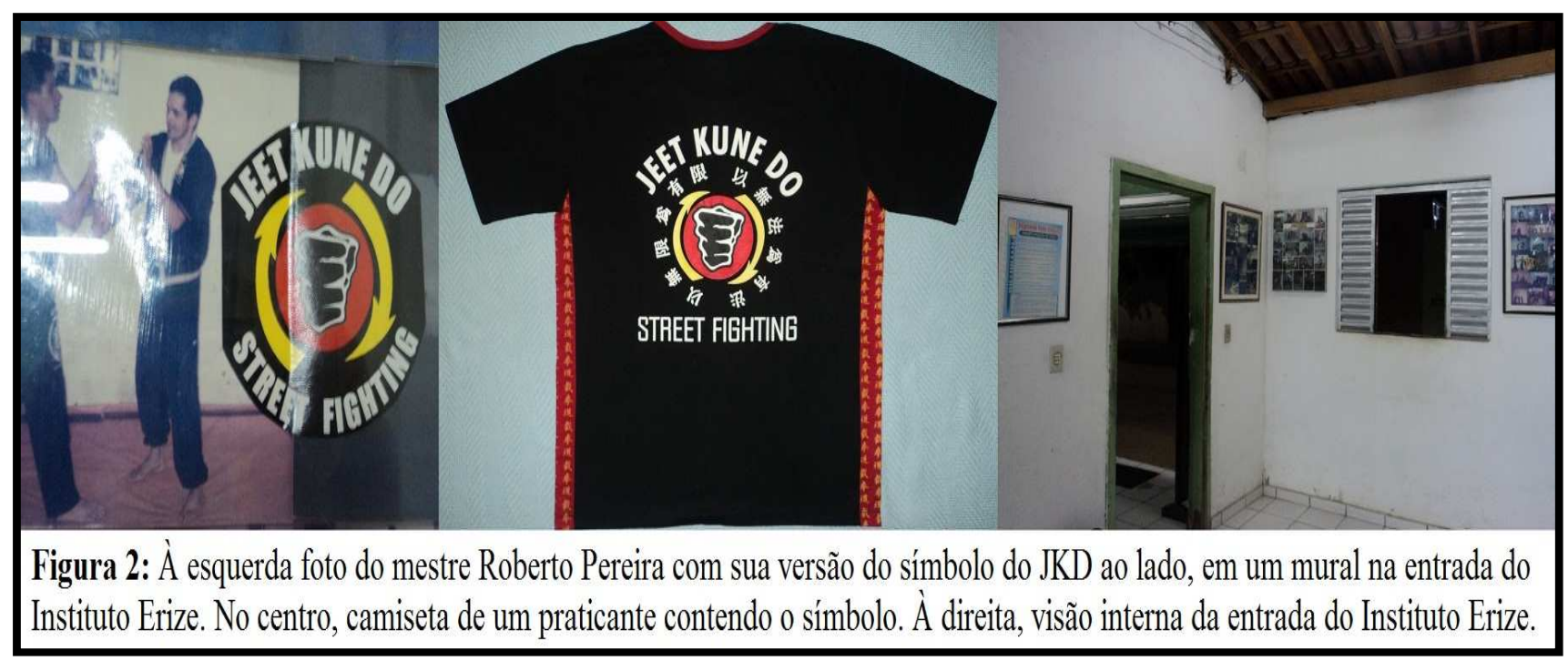

O bambu não tem somente significado de arma (bastão) mas também um significado de origem religiosa taoísta e budista: "ser flexível, ter resistência. 0 oco, 
que é o vazio. Usar como, vamos supor, o equilíbrio dos dois lados. Tá sempre tentando equilibrar" (Ruysdael em entrevista concedida em janeiro de 2011). Sua resposta aparece como um empréstimo híbrido da cosmologia budista e taoísta, o elemento central é budista - o vazio (shunyata) - mas o equilíbrio e o ser flexível têm caráter taoísta:

A retidão inigualável do bambu, a perfeição de seu élan em direção ao céu, o espaço vazio entre seus nós - imagem da shunyata, da vacuidade do coração - simbolizam, para o budista, e mesmo para o taoísta, os caracteres e o alvo de sua maneira de agir interior (CHEVALIER; GHEERBRANT, 2008, p. 118).

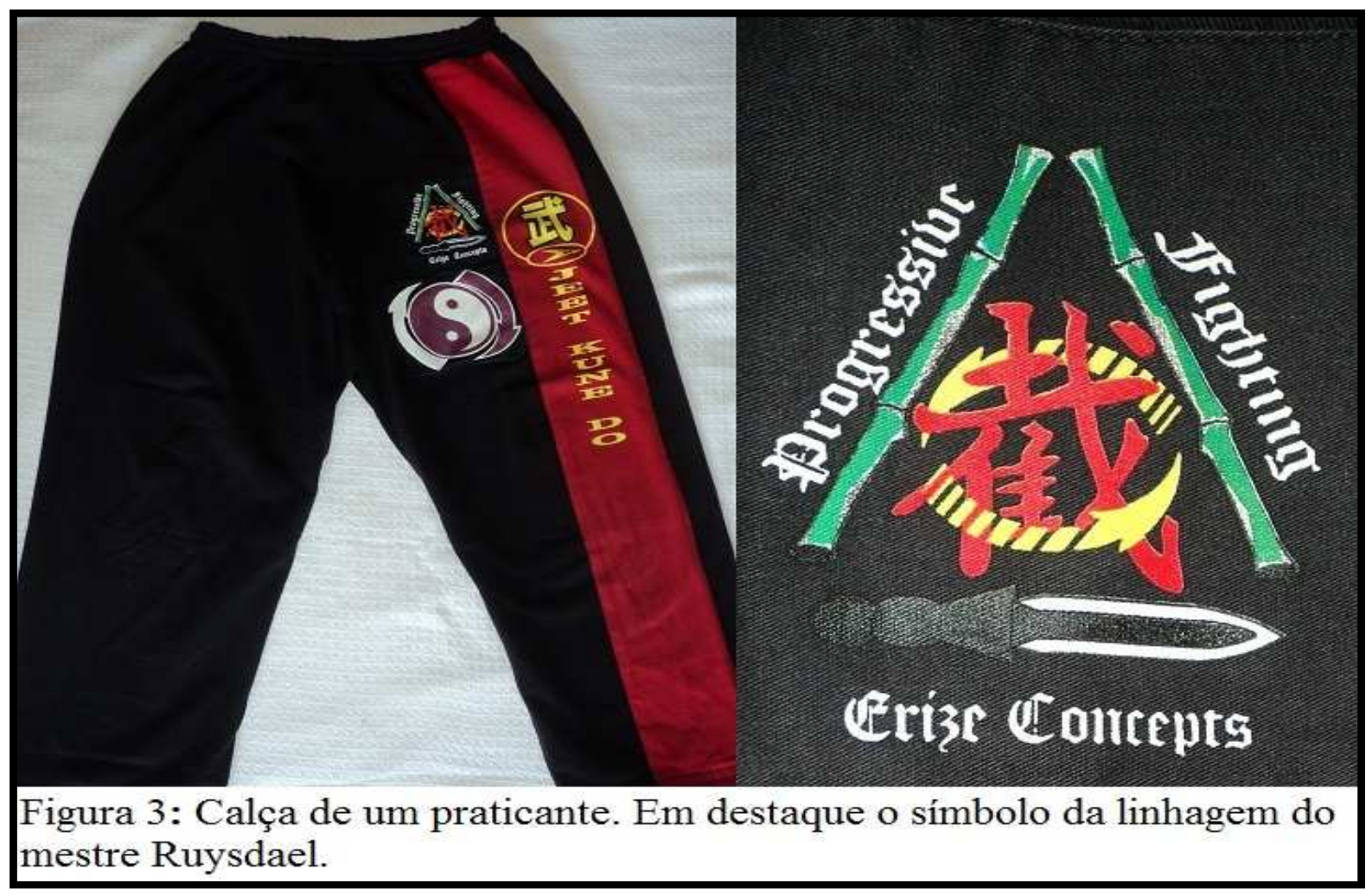

Progressive Fighting, em termos "nativos", faz menção à ideia de constante adaptação e evolução dessa prática. Já Erize Concepts diz respeito ao JKD na compreensão do mestre Ruysdael, da sua forma de ver os conceitos e noções teóricas e técnicas de Bruce Lee (e outros mestres, como Dan Inosanto). 0 termo "Concepts" também faz referência a uma questão que não é muito clara no universo dos praticantes dessa arte marcial, que é divisão entre JKD “original” e JKD “concepts”. 


\section{A busca pela eficácia e pela autonomia criativa: etnografia dos treinos de Jeet Kune Do em Montes Claros}

Para Geertz (1989), os símbolos manifestam o ethos e a visão de mundo de um grupo. Ethos seria "o tom, o caráter, e a qualidade de sua vida, seu estilo moral, e estético e sua disposição, é a atitude subjacente em relação a ele mesmo e ao mundo que a vida reflete" (p. 143), ou seja, todo o comportamento singular em uma determinada etnia ou grupo, sempre conforme a sua visão de mundo, que é "o quadro que elabora das coisas como elas são na simples realidade, seu conceito da natureza, de si mesmo, da sociedade" (idem, p. 144). Dessa forma:

\footnotetext{
[...] o ethos torna-se intelectualmente razoável porque é levado a representar um tipo de vida implícito no estado de coisas real que a visão de mundo descreve, e a visão de mundo torna-se emocionalmente aceitável por se apresentar como imagem de um verdadeiro estado de coisas do qual esse tipo de vida é expressão autêntica (idem, ibidem).
}

Entendemos que os conceitos e as noções presentes nos símbolos analisados fazem parte da visão de mundo dos praticantes. Mas não é toda a visão de mundo deles, mesmo porque todos exercem outras atividades como estudar, trabalhar, ou atividades religiosas. Para compreender a visão de mundo desses praticantes de JKD, buscamos, mediante observação etnográfica, mapear o ethos. Buscando interpretar as evidências simbólicas que constituem o ethos desses praticantes, norteamos-nos no círculo hermenêutico proposto por Geertz (2009, p. 87), em que entrelaçamos o mais adequadamente possível conceitos de experiênciapróxima - do ponto de vista dos "nativos" - e experiência-distante - conceitos acadêmicos.

Contextualizando a prática do JKD em Montes Claros, notamos algumas características gerais dos treinos: acontece num ambiente com músicas mais aceleradas, como rock e músicas eletrônicas, começando com exercícios aeróbicos para aquecimento, treinamento com técnicas rápidas e de forma dinâmica. Há liberdade para o praticante executar as técnicas da forma em que melhor se adapta. A busca por uma eficácia marcial e por uma autonomia criativa (fluir) pode ser descrita como a característica central do ethos dos praticantes de JKD em Montes Claros.

Com base na observação de um treino de JKD em Belo Horizonte (MG) em julho de 2010 e nas conversas com diversos praticantes pelo Brasil, arriscamos 
afirmar que a busca por eficácia é característica central em todos os praticantes de JKD que treinam há um tempo significativo. Quanto ao fluir, observamos somente em Montes Claros. Acreditamos que possivelmente isso se dá pelo fato de o mestre Ruysdael ser budista, como também pela sua aproximação com culturas do extremo oriente, principalmente com a cultura japonesa - ele também é professor de ninjutsu, uma arte marcial japonesa.

Sobre a eficácia, podemos encontrar já nos escritos de Bruce Lee um forte apelo para uma funcionalidade nas artes marciais. Ele enfatizava esse ponto porque entendia que as técnicas seriam usadas em situações reais: num assalto, numa perseguição, em uma briga de rua. Isso pode ser confirmado em seus livros, como o Bruce Lee's Fight Method (LEE; UYEHARA, 1996), contendo técnicas acompanhadas de fotos ilustrativas que ensinam a surpreender possíveis assaltantes. No caso dos treinos de JKD em Montes Claros, é uma constância nas falas do mestre a questão da eficiência: em diversas situações, mas principalmente na prática da "técnica livre" (um "parceiro" ataca, e outro defende, desvia e contra-ataca da forma que quiser), sempre é perguntado aos praticantes "isso é funcional?", "como você aplica isso na rua?"; e também ocorre de forma inversa, os praticantes perguntam ao professor com certa frequência se essa ou aquela técnica é funcional. Um exemplo disso foi em um treinamento (18/9/2010) em que um praticante mais graduado fez o seguinte comentário após outro praticante mostrar uma técnica a pedido do mestre: "na arte marcial, a gente tem que separar o que é funcional do que é cinematográfico". Esse comentário demonstra que os praticantes - ou pelo menos esse entendem que na prática o importante é a eficácia e a funcionalidade das técnicas.

Notamos a seguinte diferença entre um praticante de JKD e outros praticantes de artes marciais que enfocam no aspecto esportivo/competitivo²: nos treinos, é comum o mestre Ruysdael ou mesmo praticantes antigos (ou seja, que se identificam com o JKD) comentarem, depois de treinar uma técnica, "e se fosse na rua?", "na rua o 'cara' não vai deixar você fazer isso" ou "na rua não dá para ficar pensan-

\footnotetext{
2 Algumas artes marciais "orientais" sofreram um processo de esportivização, como o Judô, o Karatê, o Sanshou e o Tae Kwon Do. Fabiana Turelli (2008), pesquisadora que estudou a pedagogia das artes marciais, classificou-as como do campo marcial-esportivo, ou seja, suas práticas são voltadas a competições e campeonatos. Segundo essa autora, também existe o campo marcial-"filosófico", sendo que as artes marciais desse campo ficam alheias a competições, estando mais centradas na "formação do guerreiro" no sentido espiritual, mental e corporal, para usar termos comuns de academias.
} 
do qual técnica fazer, apenas tem que fazer". No Instituto Erize, observamos um imaginário coletivo de que se devem utilizar técnicas eficientes, pois, quando precisarem usá-las (e não será em campeonatos), elas devem ser úteis para situações perigosas (como as da rua). Essa eficiência está representada no símbolo da linhagem do mestre Ruysdael (figura 3), mais exatamente no ideograma jeet (interceptar): interceptar o perigo, o problema, o golpe do adversário.

Em contrapartida, "mas isso não vale em campeonato, [você] vai ser desclassificado" disse um praticante depois de ter treinado um contra-ataque mais "agressivo". Nas entrevistas, quando indagado sobre a importância dessa prática na sua vida, esse mesmo praticante disse que para ele o JKD era um hobby. Com sua resposta percebemos que, quando alguém frequenta os treinos e experimenta um sentimento de pertença para com o grupo dos praticantes de JKD, ele incorpora ou acrescenta a si a visão de mundo e o ethos do grupo. Desse modo a incorporação da cosmologia e, por consequência, de elementos religiosos presentes na prática dependem de um sentimento (feeling) de integração com o grupo e com a prática. Com ele, então, não houve, ainda, esse sentimento de pertença, estando sua visão de mundo voltada para competições.

Alguns praticantes nas entrevistas mostraram um alto grau de identificação, como uma entrevistada que, quando questionada sobre o uso das camisetas da academia fora do treino respondeu: "tenho orgulho de usar a camiseta do 'jeet"'. Outro entrevistado, quando indaguei qual era a importância do JKD para sua vida, respondeu: "hoje o Jeet Kune Do é minha religião". Os dois, assim como mais nove dos onze entrevistados, apresentaram não só um ethos centrado na busca por eficácia, como também um grau elevado de absorção dos elementos religiosos (uns mais, outros menos), que vai desde a procura por uma religião (como no primeiro caso citado, o budismo) ao interesse pelos animes (desenhos animados japoneses).

O segundo aspecto central é o fluir, ou autonomia criativa. Para Bruce Lee "é a capacidade criativa do ser humano que o distingue de todos os outros animais" (2007, p. 24). E, para ele, a criatividade está estreitamente ligada à liberdade (ou ausência de condicionamentos externos). 0 símbolo do JKD (figura 1) expressa tal concepção. Como escreveu magistralmente Durand, é no "poder poético do símbo- 
lo" que melhor se define a liberdade humana, na "experiência do símbolo" a "liberdade é criadora de um sentido" (2000, p. 33; grifo do autor).

No Instituto Erize, o mestre Ruysdael pede constantemente para "deixar fluir" nos treinos das técnicas. Esse fluir é representado pelos símbolos na academia (figuras 1, 2 e 3) estando na base do JKD. Além disso, transmite o significado de não estar preso a nenhum condicionamento, nenhum modelo pré-estabelecido. Em textos taoístas e no Tao do Jeet Kune Do, encontramos o termo "vazio" como sinônimo de fluidez: é como se ao ficar vazio o tao possa fluir livremente e conduzir naturalmente os seres, segundo os escritos taoístas de Chuang Tse e Lao Tse.

Observamos durante os treinos, que muitos praticantes se preocupam bastante com este "deixar fluir" repetido pelo mestre. Perguntamos nas entrevistas sobre esta frase do mestre: "Você se preocupa em 'deixar fluir'? Por quê?" Dos onze, nove responderam positivamente e dois disseram que "de vez em quando", explicando que o nervosismo deles os atrapalha. Das respostas positivas, destacamos as seguintes, sendo de dois praticantes mais antigos. Esta primeira é de F. (primeiro aluno de Ruysdael):

Fluir, que é o que Ruy passa, que é o que a gente pratica no Jeet Kune Do, é que depois que você repete as técnicas várias vezes, depois que você repete, ela se torna impensável. Você é... você realiza o movimento sem pensar. Então fica mais automático, fica mais fácil de agir. Porque se você for pensar na técnica número um, posição dois, ângulo três, na briga de rua não funciona isso, então você na briga de rua tem que agir sem pensar, é o principio do Jeet Kune Do. Um dos [princípios], é fluir. Importante.

0 praticante em questão apresenta segurança tanto na forma de falar quanto no conteúdo implícito na sua fala, ou seja, sua visão de mundo. Com essa fala podemos perceber como elementos de uma cultura estranha à sua são recebidos, aceitos e apropriados à sua visão de mundo por meio das artes marciais. Há, assim, uma identificação com a cosmologia do JKD, com seus elementos simbólicos, o praticante reconhece-se no símbolo da fluidez, e a fluidez faz com que ele se reconheça na prática, daí uma duplicidade. Essa fala ainda alude à questão da rua, remetendo à ligação entre o fluir e à busca por eficácia. A resposta de C. à mesma pergunta reitera essas questões:

Tenho, e isso aí é a partir... com o tempo você vai notando que realmente essa história de fluir... realmente flui. Você acaba, você acaba assim, realmente percebendo que a- 
quilo que você tá fazendo ali já nem é mais assim, pensando, é mais ser quase que instintivo.

Essa fala alude implicitamente a uma incorporação dos elementos religiosos e estrangeiros (fluir taoísta, chinês), apontando para uma possível orientalização do imaginário dos praticantes de JKD. Peter Burke (2003, p. 77) afirma que "pode ser útil distinguir quatro estratégias, modelos ou cenários possíveis de reação a 'importações' ou 'invasões' culturais. Essas reações são aceitação, rejeição, segregação e adaptação".

Observamos que os praticantes reagem principalmente com aceitação e adaptação, dois casos de segregação e nenhum de uma completa rejeição. Como exemplos de aceitação, podemos citar P., que afirmou em nosso questionário que utiliza o "ensinamento do yin e yang para o equilíbrio [psicossocial]". Já sobre a reação de adaptação, observamos A., que utiliza ensinamentos do Budismo para auxiliar o próprio comportamento, e N. que afirmou (no questionário) usar princípios budistas e confucionistas de paz e cuidado com o "próximo". O praticante F., que é cristão evangélico, apresenta uma reação do tipo segregação, uma vez que afirmou separar "religião de arte marcial", e, ainda, que estuda somente o básico sobre a história das artes marciais, pois "na China, no Japão, na Coreia é muito complicado, porque a arte marcial é ligada com religião" e, por isso, afirma:

\footnotetext{
Eu já conheço o básico, e desse básico eu tô satisfeito. Porque se eu for entrar na questão de estudar a cultura oriental, eu vou tá assim, é... mergulhando [em] muita parte da religiosidade, [por]que China e Japão é muito isso. É mais religião que artes marciais, então tá muito ligado. Então o interessante das artes marciais é aprender a me defender, só isso e nada mais. Adoração, religião eu já tenho o suficiente, já tô tranquilo, já tô garantido na minha salvação.
}

Contudo, recentemente, ao receber uma graduação mais alta, pediu para o mestre Ruysdael raspar sua cabeça, em homenagem aos "monges do mosteiro de Shaolin, que dedicam sua vida no treinamento das artes marciais". Assim, ele realiza uma negociação cultural, escolhendo o que lhe interessa e rejeitando o que não convém, ou aquilo com o que não se identifica.

Dessa forma, observamos algumas reações dos praticantes de JKD após o contato com conteúdo religioso presente nessa prática. Acreditamos serem essas 
as principais reações que acontecem com os praticantes do Instituto Erize de Artes Marciais. Percebemos, então, como os praticantes interpretam pessoalmente a busca pela eficácia e pela autonomia criativa.

\section{Considerações finais}

Baseados em nossas análises e interpretações do comportamento, dos símbolos e das falas dos praticantes de JKD em Montes Claros, afirmamos que, em sua maioria, os praticantes incorporam parte significativa dos elementos religiosos presentes nessa arte marcial. Percebemos alguma incorporação desses elementos em diversas formas: numa procura por respostas no budismo, após ouvir explicações sobre essa religião nos treinos, ou - depois de tanto ouvir o mestre Ruysdael pedir para fluir quando praticam as técnicas - na compreensão que "essa história de fluir realmente flui", como disse um praticante, e dessa forma remetendo a uma concepção religiosa vinda do taoísmo, o vazio/fluidez.

Os conceitos religiosos difundidos por meio do JKD, para além dos contextos onde nasceram, transmitiram parcialmente a religiosidade e o imaginário de tradições asiáticas - no caso, chinesa (taoísmo), japonesa (zen budismo) e indiana (também o budismo e Krishnamurti) - para o sertão norte-mineiro. Isso não quer dizer que os praticantes de JKD são budistas ou taoístas, mas que experimentam de alguma forma, as suas cosmologias e gestos simbólicos por meio dessa prática.

Baseados nos resultados aqui mostrados podemos cogitar que, muito provavelmente, a prática das artes marciais em Montes Claros, presente desde meados do século XX, tem contribuído para a divulgação indireta de religiosidades e religiões de tradição asiática como o budismo, hinduísmo, taoísmo ou shintoísmo. Isso se deve, possivelmente, a um imaginário religioso difuso presente na transmissão das técnicas e ensinamentos dentro de cada academia de arte marcial.

\section{Referências}

APOLLONI, R. W. (2004). Shaolin à brasileira:estudo sobre a presença e a transformação de elementos religiosos orientais no kung-fu praticado no Brasil. Dissertação (Mestrado em Ciências da Religião) - Pontifícia Universidade Católica de São Paulo, São Paulo. 
BORGES, C. (2011). Umbanda sertaneja:cultura e religiosidade no sertão nortemineiro. Montes Claros, Unimontes.

BuRKE, P. (2003). Hibridismo cultural. São Leopoldo, Unisinos.

Canclini, N. G. (2006). Culturas Híbridas: estratégias para entrar e sair da modernidade. São Paulo, EDUSP.

CARneiro, I. L. B. (2009). A antropologia filosófica na perspectiva de Jiddu Krishnamurti:a educação como elemento fundante do homem. Tese (Doutorado em Educação) - Universidade Federal da Bahia, Salvador.

Chevalier, J.; Gheerbrant, A. (2008). Dicionário de símbolos. Rio de Janeiro, José Olympio.

Costa, J. B. A. (2003). Mineiros e baianeros: englobamento, exclusão e resistência. Tese (Doutorado em Antropologia Social) - Universidade de Brasília, Brasília.

DurAnd, G. (2000). A imaginação simbólica. Lisboa, Edições 70.

tes. . (2002). As estruturas antropológicas do imaginário. São Paulo, Martins Fon-

GEERTz, C. (1989). A interpretação da culturas. Rio de Janeiro, LTC.

_. (2009). O saber local:novos ensaios em antropologia interpretativa. Petrópolis, Vozes.

LAoTsÉ. (1988).Tao Te Ching: o livro do Tao e sua virtude. Trad. de Marcos Martinho dos Santos.São Paulo, Attar.

LEE, B. (2003). O Tao do Jeet Kune Do. São Paulo, Conrad. (2007). Aforismos. São Paulo, Conrad.

Lee, B.; Uyehara, M. (1996). Bruce Lee's Fight Method. 38. ed. 4 vols. Santa Clarita, California, Ohara Publications.

Lopes, M. A. (2006). Bruce Lee: definitivo. São Paulo, Conrad.

Merton, T. (1977). A via de Chuang Tzu.Petrópolis, Vozes.

SAID, E. W. (1990). O orientalismo: o oriente como invenção do ocidente. São Paulo, Companhia das Letras.

SHAHAR, M. (2003). "Evidências da prática marcial em Shaolin durante o Período Ming”.Rever - Revista de Estudos da Religião, n. 4, p. 93-144. Disponível em: <www.pucsp.br/rever/rv4 2003/p shahar.pdf>. Acesso em: 26 jan. 2011.

Turelli, F. C. (2008). Corpo, domínio de si, educação:sobre a pedagogia das lutas corporais. Dissertação (Mestrado em Educação) - Universidade Federal de Santa Catarina, Florianópolis.

Recebido em setembro/2011

Aprovado em fevereiro/2012 